\title{
Pola pengobatan antitrombotik pada pasien stroke iskemik dengan fibrilasi atrium berdasarkan skor CHA2DS2-VASc dan skor HAS BLED
}

\author{
Rizaldy Taslim Pinzon', Gusti Ayu Putu Ika Bella Saptaning Astyari', Lidwina Tarigan ${ }^{1}$ \\ ${ }^{I}$ Rumah Sakit Bethesda, Jalan Jend.Sudirman No.70 Yogyakarta, Indonesia \\ ${ }^{2}$ Fakultas Kedokteran Universitas Kristen Duta Wacana \\ Jln.Dr.Wahidin Sudiro Husodo Yogyakarta
}

Submitted: 11-09-2016

Reviewed: 14-12-2016

Accepted: 17-05-2017

\begin{abstract}
ABSTRAK
Stroke yang berhubungan dengan fibrilasi atrium dan kardioemboli cenderung bermanifestasi lebih berat, berisiko tinggi berulang, serta mortalitasnya lebih tinggi. Pemberian antikoagulan lebih dianjurkan pada stroke iskemik dengan fibrilasi atrium sebagai upaya pencegahan, baik primer maupun sekunder. Skor stratifikasi CHA2DS2-VASc (Congestive Heart Failure, Hypertension, Age $\geq$ 75, Diabetes, Stroke, Vascular Disease, Sex-Female) digunakan untuk menseleksi pasien pada risiko terkena stroke iskemik untuk pemilihan antitrombotik yang tepat. Pada risiko untuk terjadinya perdarahan skor HAS BLED (Hypertension, Abnormal liver/ kidney function, Stroke, Bleeding tendency, Elderly, Drug/ Alcohol) digunakan untuk meramalkan risiko perdarahan. Penelitian di Indonesia terkait penggunaan skoring dalam pemilihan anti thrombotik belum banyak dilakukan. Tujuan penelitian ini untuk mengukur prevalensi penggunaan antitrombotik berdasarkan pada skor CHA2DS2-VASc dan skor HAS BLED pada pasien stroke dengan fibrilasi atrium. Penelitian ini merupakan studi deskriptif dengan rancangan potong lintang (cross sectional). Sampel diperoleh dari stroke registry dan rekam medis dari pasien di Poli Saraf Rumah Sakit Bethesda Yogyakarta pada tahun 2009-2016. Data dianalisis menggunakan analisis univariat. Data diperoleh dari 77 pasien stroke iskemik dengan fibrilasi atrium yang terdiri dari 33 laki-laki $(42,8 \%)$ dan 44 perempuan $(57,1 \%)$, proporsi terbesar ada pada pasien berusia $>70$ tahun $(33,3 \%)$. Hasil analisis univariat menunjukkan bahwa penggunaan antiplatelet ada pada $71(92.2 \%)$ pasien, penggunan antikoagulan $6(7,7 \%)$ pasien, serta nilai skor CHA2DS2-VASc $0=3(3,8 \%), 1=18(22,5 \%), \geq 2=56(70,1 \%)$, pada skor HAS BLED $0=7(8,8 \%), 1=27(33,8 \%), 2=29(36,3 \%), 3=13(16,3 \%), 4=1$ (1,3\%). Kesimpulan skor CHA2DS2VASc dan skor HAS BLED belum mempengaruhi penggunaan antitrombotik pada pasien stroke iskemik dengan fibrilasi atrium di RS Bethesda Yagyakarta.
\end{abstract}

Kata kunci: stroke iskemik, skor CHA2DS2-VASc, skor HAS BLED, fibrilasi atrium.

\section{ABSTRACT}

Stroke associated with atrial fibrillation and cardioembolism tend to manifest more severe, recurrent high risk, and higher mortality. Anticoagulation is recommended in ischemic stroke in atrial fibrillation for prevention, both primary and secondary. Stratification score CHA2DS2-VASc (Congestive Heart Failure, Hypertension, Age $\geq 75$, Diabetes, Stroke, Vascular Disease, Sex-Female) is used to select patients at risk of ischemic stroke for the selection of appropriate antithrombotic.

Penulis korespondesi:

Rizaldy Taslim Pinzon

Rumah Sakit Bethesda, Jalan Jend.Sudirman No.70 Yogyakarta, Indonesia

Email: drpinzon17@gmail.com 
The risk of bleeding is measure with HAS BLED (Hypertension, Abnormal liver/ kidney function, Stroke, Bleeding tendency, Elderly, Drug/ Alcohol) score. Previous studies are very limited in research of anti thrombotic use in cardioembolic stroke. Aim this study is Measure the utilization of antittrombothic medication based on CHA2DS2-VASc score and HAS BLED in ischemic stroke patient with atrial fibrillation. This study is a cross sectional. Samples were obtained from the stroke registry and electronic medical records of patients at the Neurology Clinic of Bethesda Hospital Yogyakarta between 2009-2016. Data was analyzed using univariat approach. Data obtained from 77 patients with ischemic stroke in atrial fibrillation which consisted of 33 men (42.8\%) and 44 women $(57.1 \%)$. The largest proportion of patients are aged $>70$ years $(33.3 \%)$. Results of univariate analysis showed that the use of antiplatelet there were $71(92.2 \%)$ patients, the use of anticoagulants $6(7.7 \%)$ patients, as well as a score CHA2DS2-VASc $0=3(3.8 \%), 1=18(22.5 \%), \geq 2=56(70.1 \%)$, the HAS BLED score of $0=7(8.8 \%), 1=27$ (33.8\%), $2=29$ (36.3\%), $3=13(16.3 \%), 4=1(1.3 \%)$. CHA2DS2-VASc and HAS BLED score are not affect the use of antithrombotic agents for ischemic stroke patient with atrial fibrillation.

Keywords: ischemic stroke, CHA2DS2-VASc score, HAS-BLED score, atrial fibrillation.

\section{PENDAHULUAN}

Kejadian stroke pada fibrilasi atrium adalah $4,5 \%$ per tahun. Dengan kematian atau disabilitas permanen lebih dari setengah. Risiko stroke bervariasi mulai dari $20 \%$ pertahun yang dihubungkan dengan risiko penyakit gagal jantung, hipertensi, usia, diabetes dan stroke sebelumnya dan TIA (Transient Ischemic Attack). Fibrilasi atrium dikaitkan erat dengan peningkatan risiko stroke iskemik dimana risiko stroke juga berhubungan erat dengan risiko pendarahan (Shahpouri et al., 2012).

Risiko stroke pada pasien fibrilasi atrium sebesar 15\% pertahun, yaitu 1,5\% pada kelompok usia 50-59 tahun dan 23,5\% pada kelompok usia 80-89. Indeks CHA2DS2-VASc dan skor HAS-BLED berguna untuk memprediksi risiko stroke dan perdarahan. Skor CHA2DS2-VASc yang semakin tinggi berarti semakin tinggi kejadian stroke. Skor diatas 2 merupakan indikasi pemberian anti koagulan. Skor HAS BLED semakin tinggi merupakan prediktor terjadinya perdarahan. Skor HAS BLED diatas 3 menunjukkan pasien risiko tinggi perdarahan (Singer et al., 2008).

Oral antikoagulan adalah agen antitrombotik unggul tetapi kurang dimanfaatkan karena ketakutan akan terjadinya perdarahan dan ketidakpastian tentang apakah pasien akan mendapatkan keuntungan pada penggunaan antikoagulan. keputusan individual pada terapi antitrombotik memerlukan pertimbangan antara risiko tromboemboli dan perdarahan (Isla et al., 2009).

Indeks CHA2DS2-VASc dan skor HAS-BLED berguna untuk memprediksi risiko stroke dan perdarahan. Skor CHA2DS2-VASc terdiri dari: Congestive heart failure (disfungsi ventrikel kiri), Hypertension, Age $\geq 75$ years (skor 2), Diabetes mellitus, Stroke history (skor 2), peripheral Vascular disease, Age between 65 to 74 years, Sex Category (female) (skor 1) (Olesen et al., 2012).

Skor HAS-BLED terdiri dari Hypertension, Abnormal renal or liver function, history of Stroke, history of Bleeding, Labile INR value, Elderly, dan antithrombotic Drugs and alcohol. Skor ini telah divalidasi pada banyak studi kohort berkorelasi baik dengan perdarahan intracranial (Gallego et al., 2012).

Evaluasi risiko perdarahan pada setiap pasien fibrilasi atrium harus dilakukan jika skor HASBLED $\geq 3$ pasien yang memiliki risiko perdarahan perlu mendapat perhatian khusus, pengawasan berkala dan upaya untuk mengoreksi faktor-faktor risiko yang dapat diubah. Skor HAS-BLED tidak digunakan untuk melakukan eksklusi pemakaian antikoagulan tetapi sebagai panduan sistematis dalam menafsir risiko perdarahan serta faktor-faktor risiko yang dapat dikoreksi seperti tekanan darah yang belum terkontrol, penggunaan aspirin atau non steroid anti inflammatory drugs (NSAID), dsb. Hal yang penting untuk diperhatikan bahwa pada skor HAS-BLED yang sama, pemberian aspirin atau warfarin memiliki risiko yang sama untuk terjadi perdarahan intrakranial dan perdarahan mayor lain. Penggabungan skor CHA2DS2-VASc dan HAS-BLED sangat bermanfaat dalam keputusan tromboprofilaksis pada praktik sehari-hari. Skor CHA2DS2-VASc diatas 2 mengindikasikan pemberian 
anti koagulan oral (Vitamin $K$ antagonist atau Non Vitamin $K$ antagonist oral anticoagulant). Skor HAS-BLED diatas 3 mengindikasikan risiko perdarahan, sehingga pemilihan Non Vitamin $K$ antagonist oral anticoagulant lebih diindikasikan (Olesen, et al., 2012, Gallego, et al., 2012).

\section{METODE PENELITIAN \\ Alat dan Bahan}

Penelitian ini menggunakan metode deskriptif cross sectional yang memakai data sekunder yaitu data electronic stroke registry dan rekam medis elektronik pasien tahun 2009 sampai tahun 2016. Sampel penelitian adalah pasien stroke iskemik dengan fibrilasi atrium di RS Bethesda Yogyakarta yang didiagnosis dengan CT (computed tomography) scan kepala dan ECG (electro cardio graph).

Diagnosis stroke dilakukan oleh dokter spesialis saraf dengan data penunjang klinik dan CT Scan. Diagnosis fibrilasi atrium ditegakkan oleh dokter ahli jantung berdasar pemeriksaan fisik kardiologi dan ECG (electro cardio graph). Diagnosis faktor risiko lain diperoleh dari pemeriksaan laboratoium terstandar.

\section{Jalannya Penelitian}

Peneliti memperoleh data dari register stroke electronic dan rekam medik elektronik RS Bethesda Yogyakarta. Data ditabulasi ke dalam instrumen penelitian. Data terkait faktor risiko vaskular lain yang dimasukkan dalam skoring dikumpulkan dari rekam medik eletronik RS Bethesda Yogyakarta. Data penggunaan obat anti thrombotik dikumpulkan dari peresepan elektronik instalasi farmasi RS Bethesda Yogyakarta. Penelitian ini mendapat surat kalayakan etik ke Komite Etik Penelitian Fakultas Kedokteran Universitas Kristen Duta Wacana dengan nomor 206/C.16/FK/ 2016.

\section{Analisis Data}

Data ditabulasi untuk melihat karakteristik dasar dan karakteristik skor CHA2DS2-VASc dan HAS-BLED. Data dianalisis menggunakan analisis deskriptif. Analisis deskriptif meliputi karakteristik data seluruh pasien.

\section{HASIL DAN PEMBAHASAN}

Data diperoleh dari 77 pasien stroke iskemik dengan faktor risiko utama fibrilasi atrium. Data karakteristik dasar seluruh subyek penelitian dapat dilihat pada Tabel I. Tabel I memperlihatkan bahwa pasien stroke iskemik dengan fibrilasi atrium lebih banyak pada kelompok perempuan, dan lebih dari $60 \%$ kasus berusia diatas 60 tahun. Penggunaan anti platelet mendominasi dari seluruh pilihn anti thrombotic yang ada. Hanya kurang dari $10 \%$ kasus yang mendapatkan anti koagulan oral (warfarin). Tidak ada kasus yang mendapatkan anti koagulan oral golongan non antagonis Vitamin K.

Deskripsi komponen skor HAS-BLED dapat dilihat pada Tabel II. Stroke merupakan kondisi utama yang pasti ada, dan meningkatkan risiko perdarahan pada penggunaan anti thrombotik. Pasien stroke iskemik dengan gangguan irama jantung memiliki usia yang relatif tua. Penelitian ini menunjukkan bahwa komponen utama setelah stroke pada skor HAS-BLED adalah usia $>65$ tahun. Nilai skor HAS-BLED yang tinggi bukan merupakan kontraindikasi penggunaan anti thrombotik karena merupakan keharusan dari clinical practice guideline, namun menjadi pedoman dokter dan petugas kesehatan lain untuk lebih hati-hati terhadap munculnya risiko perdarahan.

Tabel II dan III di bawah menggambarkan karakteristik dasar seluruh sampel penelitian yang telah dianalisis secara deskriptif. Tujuh puluh tujuh pasien yang memenuhi kriteria inklusi dan eksklusi masuk dalam penelitian ini, terdiri dari 33 pasien laki-laki $(42,8 \%)$ dan 44 pasien perempuan $(57,1 \%)$. Rentang usia terbanyak adalah $>70$ tahun yaitu sebanyak 24 pasien $(33,3 \%)$. Tabel di bawah juga memperlihatkan $72,7 \%$ pasien memiliki nilai skor CHA2DS2-VASc $\geq 2,44,2 \%$ pasien memiliki skor HAS BLED > 3 .

Pada pasien fibrilasi atrium yang sudah mengalami stroke, maka pasien tersebut akan memiliki skor CHA2DS2-VASc dan HAS-BLED yang tinggi. Pasien yang memiliki risiko tinggi untuk terjadinya kardioemboli akan memiliki risiko perdarahan yang lebih tinggi pula. Pada penelitian ini 
diperoleh data bahwa skor CHA2DS2-VASc $\geq 2$ dijumpai pada $100 \%$ kasus karena telah memiliki riwayat stroke.

Tabel I. Data karakteristik dasar pesien stroke iskemik dengan faktor risiko utama fibrilasi atrium

\begin{tabular}{|c|c|c|}
\hline Karakteristik Pasien & $\mathrm{n}=77$ & $\%$ \\
\hline \multicolumn{3}{|l|}{ Jenis kelamin } \\
\hline Laki-laki & 33 & $42,1 \%$ \\
\hline Perempuan & 44 & $57,1 \%$ \\
\hline \multicolumn{3}{|l|}{ Usia } \\
\hline 40-50 tahun & 3 & $4,16 \%$ \\
\hline 51-60 tahun & 20 & $30,5 \%$ \\
\hline $61-70$ tahun & 23 & $31,9 \%$ \\
\hline$>70$ tahun & 24 & $33,3 \%$ \\
\hline \multicolumn{3}{|l|}{ Serangan stroke } \\
\hline Pertama & 53 & $68,8 \%$ \\
\hline Berulang & 24 & $31,2 \%$ \\
\hline \multicolumn{3}{|l|}{ Skor CHA2DS2-VASc } \\
\hline $0-1$ & 0 & $0 \%$ \\
\hline$\geq 2$ & 77 & $100 \%$ \\
\hline \multicolumn{3}{|l|}{ Skor HAS-BLED } \\
\hline 1 & 34 & $44,2 \%$ \\
\hline 2 & 29 & $37,7 \%$ \\
\hline 3 & 13 & $16,8 \%$ \\
\hline 4 & 1 & $1,3 \%$ \\
\hline \multicolumn{3}{|l|}{ Agen Antiplatelet tunggal } \\
\hline Aspirin & 48 & $62,3 \%$ \\
\hline Clopidogrel & 16 & $20,7 \%$ \\
\hline \multicolumn{3}{|l|}{ Agen Antiplatelet } \\
\hline Aspirin + Clopidogrel & 7 & $9,2 \%$ \\
\hline \multicolumn{3}{|l|}{ Agen Antikoagulan } \\
\hline Warfarin & 6 & $7,8 \%$ \\
\hline
\end{tabular}

Tabel II. Karakterisktik komponen masing-masing skor HAS BLED pada pasien stroke iskemik dengan faktor risiko utama fibrilasi atrium

\begin{tabular}{llll}
\hline Karakteristik skor HAS-BLED & Skor & $\mathbf{N = 7 7}$ & \% \\
\hline Hipertensi (> 160 mmHg) & 1 & 3 & $3,9 \%$ \\
$\begin{array}{l}\text { penurunan fungsi ginjal/ penurunan } \\
\text { fungsi hati }\end{array}$ & 1 atau 2 & 0 & $0 \%$ \\
$\begin{array}{l}\text { Stroke } \\
\text { Bleeding (perdarahan sebelumnya) }\end{array}$ & 1 & 77 & $100 \%$ \\
$\begin{array}{l}\text { INRs yang tidak menetap (tidak stabil / } \\
\text { tingginya INRs atau buruknya waktu } \\
\text { terapeutik <60\%). }\end{array}$ & 1 & 0 & $0 \%$ \\
$\begin{array}{l}\text { Usia >65 tahun } \\
\begin{array}{l}\text { Obat-obatan (penggunaan obat } \\
\text { antiplatelet, NSAID) dan }\end{array}\end{array}$ & 1 & 0 & $0 \%$ \\
Alkohol & 1 atau 2 & 55 & $44,2 \%$ \\
\hline
\end{tabular}


Tabel III. Deskriptif skor CHA2DS2-VASc pada pasien stroke iskemik dengan faktor risiko fibrilasi atrium

\begin{tabular}{llll}
\hline Karakteristik skor CHA2DS2-VASc & Skor & N=77 & \% \\
\hline $\begin{array}{l}\text { Gagal jantung kongestif / penurunan } \\
\text { fungsi ventrikel kiri }\end{array}$ & 1 & 5 & $6,5 \%$ \\
Hipertensi (>140/90 mmHg) & 1 & 28 & $36,3 \%$ \\
Usia >75 tahun & 2 & 15 & $19,5 \%$ \\
Diabetes militus (>126 mg/dl) & 1 & 1 & $1,3 \%$ \\
Stroke / TIA / tromboemboli & 2 & 77 & $100 \%$ \\
$\begin{array}{l}\text { Penyakit vaskular (pernah mengalami } \\
\text { infark miokard, penyakit arteri perifer) }\end{array}$ & 1 & 5 & $6,5 \%$ \\
Usia 65-74 tahun & 1 & 36 & $46,7 \%$ \\
\hline
\end{tabular}

Tabel III memperlihatkan bahwa semua pasien memiliki skor diatas 2 karena semua pasien memiliki riwayat stroke. Perbedaan proporsi pasien hipertensi antara skor CHA2DS2-VASc dan HASBLED terjadi karena perbedaan cut-off kriteria hipertensi antara kedua skor tersebut. Skor untuk hipertensi dan usia lanjut adalah proporsi terbesar kedua dan ketiga dalam sistem skoring CHA2DS2VASc.

Panduan praktek klinik menunjukkan bahwa rekomendasi untuk pilihan anti thrombotik pada pasien fibrilasi atrium untuk mencegah stroke adalah anti koagulan (Singer, et al., 2008, Isla et al., 2009). Pada penelitian ini diperoleh data bahwa anti thrombotik utama yang dipilih adalah anti platelet (aspirin dosis rendah dan clopidogrel). Anti koagulan oral dalam sediaan warfarin (antagonis vitamin K) hanya diberikan pada 7,8\% kasus. Tidak ada pasien pada penelitian ini yang menggunakan anti koagulan oral yang bukan antagonis vitamin $\mathrm{K}$.

Berdasarkan hasil penelitian didapatkan bahwa rata-rata usia terbanyak yang terkena stroke iskemik adalah pada usia $\geq 65$ tahun. Insidensi stroke iskemik meningkat sesuai dengan pertambahan usia. Banyaknya pasien stroke yang berusia tua dikarenakan pada usia $>50$ tahun timbunan plak aterosklerosis semakin bertambah dan dapat berefek timbulnya trombus yang sewaktu-waktu bisa terlepas menjadi emboli, pembuluh darah orang yang lebih tua cenderung mengalami perubahan secara degeneratif dan mulai terlihat hasil dari proses aterosklerosis. Cepat atau lambatnya proses ini yang dapat menjadi pencetus stroke (SIGN, 2012 Kernan et al., 2014).

Pada penelitian ini angka kejadian stroke pada perempuan lebih tinggi dibandingkan lakilaki, yaitu 44 orang perempuan $(57,1 \%)$ dan 35 orang laki-laki $(42,8 \%)$. Risiko terjadinya stroke pada laki-laki lebih tinggi dibandingkan perempuan, namun dari penelitian-penelitian yang dilakukan didapatkan hasil yang beragam. Penelitian sebelumnya mendapatkan angka kejadian stroke pada laki-laki lebih tinggi dibandingkan perempuan (Kernan et al., 2014).

Pada penelitian ini didapatkan bahwa jumlah sampel dengan serangan stroke pertama adalah sebanyak $68,8 \%$ dan stroke ulangan sebanyak $31,2 \%$, hal ini nantinya akan berpengaruh terhadap pemilihan jenis obat antiplatelet atau antikogulan yang nantinya akan diberikan kepada pasien.

Pada skor CHA2DS2-VASc yang terdiri dari nilai 0 hingga maksimum poin 9, didapatkan hasil pada penelitian bahwa pada sampel dengan skor 0-1 adalah $0 \%, 22,5 \%$, pada jumlah skor 2 sebesar $28,8 \%$, pada skor 3 sebasar $41,3 \%$ dan skor 4 sebesar $29,9 \%$. Hal inilah yang nantinya berperan dalam pemilihan antiplatelet ataupun antikoagulan yang sesuai.

Pada skor HAS BLED didapatkan data bahwa sebesar $0 \%$ memiliki jumlah skor 0 , pada jumlah skor 1 sebesar 43,8 \%, pada jumlah skor 2 sebesar 39,3\%, pada jumlah skor 3 sebesar 15,6 \% dan 
jumlah skor 4 sebesar 1,3\%. Pada skor HAS- BLED dijadikan patokan dalam menilai kemungkinan terjadinya risiko perdarahan saat akan dilakukan pengobatan dengan menggunakan agen antikoagulan ataupun antiplatelet. Pada kasus dengan risiko perdarahan yang tinggi, maka dipilih anti koagulan yang memiliki risiko perdarahan yang lebih minimal. Kajian sistematis dan panduan praktek klinik terdahulu memperlihatkan bahwa anti koagulan oral non antagonis vitamin $\mathrm{K}$ lebih sedikit risiko perdarahannya dibanding warfarin.

Evaluasi risiko perdarahan pada pasien fibrilasi atrium harus dilakukan. Skor HAS-BLED tidak digunakan untuk melakukan eksklusi pada penggunaan antikoagulan tetapi sebagai panduan sistematis dalam menafsirkan risiko perdarahan dan memikirkan faktor-faktor risiko yang dapat dikorelasi seperti tekanan darah yang belum terkontrol dan penggunaan aspirin atau NSAIDS. Pasien dengan risko perdarahan yang tinggi lebih dipertimbangkan untuk mendapat anti koagulan non antagonis vitamin $\mathrm{K}$ (mis: Rivaroxaban) (Gray, 2012, Martin, 2016).

Penggunaan agen antiplatelet pada pasien stroke iskemik dengan fibrilasi atrium di RS Bethesda Yogyakarta mendominasi pada pilihan anti thrombotik. Penggunaan anti koagulan oral hanya dijumpai pada 7,8\%. Panduan praktek klinik dan kajian sistematis menunjukkan bahwa anti koagulan oral adalah lebih efektif daripada anti platelet (Hankey, 2010, Martin, 2016).

Anti platelet ganda pada beberapa penelitian lebih efektif daripada anti platelet tunggal. Ini menjadi salah satu pertimbangan penggunaan anti platelet ganda pada penelitian ini (Gouya, 2014, Yang, 2016). Jenis antikoagulan yang dipakai pada penelitian ini adalah warfarin tablet $2 \mathrm{mg}$. Pada penelitian ini didapatkan bahwa penggunaan warfarin adalah sebesar 7,8 \% dari 77 sampel. Tidak ada pasien yang mendapatkan anti koagulan oral non antagonis vitamin K. Pada pasien stroke iskemik dengan serangan stroke, adanya fibrilasi atrium yang persisten atau permanen, maka antikoagulan direkomendasikan menjadi standar terapi pencegahan sekunder. Terapi antikoagulan yang diberikan adalah adjusted-dose warfarin, dengan target INR 2,5 (range 2,0-3,0). Jika pasien intoleransi terhadap penggunaan warfarin atau memiliki risiko perdarahan, maka direct thrombin inhibitor atau faktor Xa inhibitor dapat digunakan sebagai pilihan terapi (Graeme, 2014, Martin, 2016).

Penelitian ini mengkonfirmasi penelitian terdahulu bahwa penggunaan anti koagulan masih sangat rendah. Penelitian pada 54 studi yang melaporkan tingkat risiko stroke dan persentase pasien yang diobati, sebagian besar menunjukkan kurangnya pemakaian antikoagulan oral untuk pasien berisiko tinggi berdasarkan pada skor CHA2DS2-VASc. Kajian sistematis dari 29 studi semua pasien dengan riwayat stroke/ transient ischemic attack harus menggunakan antikoagulan oral sesuai dengan pedoman yang diterbitka. Hasil kajian menunjukkan 21 dari 29 studi melaporkan tingkat pengobatan antikoagulan oral di bawah 60\% (kisaran 19\% -81,3\%) (Isla, 2009).

Penelitian ini memiliki kelemahan karena penggunaan data sekunder, dan tidak mempertimbangkan jenis fibrilasi atrium. Penelitian berikutnya dengan melihat apakah ketepatan pemilihan anti thrombotik akan berpengaruh terhadap luaran klinik perlu dilakukan. Penelitian ini menjadi salah satu sumber pustaka untuk menjustifikasi program edukasi yang lebih baik terkait pemilihan anti thrombotik pada pasien stroke iskemik dengan faktor risiko utama fibrilasi atrium.

\section{KESIMPULAN}

Pemilihan anti koagulan oral berdasar pada skor CHA2DS2-VASc dan HAS-BLED pada pasien stroke dengan faktor risiko fibrilasi atrium masih rendah proporsinya.

\section{DAFTAR PUSTAKA}

Gallego, P., Roldan, V., Torregrosa, J.M., et al., 2012, Relation of the HAS-BLED bleeding risk score to major bleeding, cardiovascular events, and mortality in anticoagulated patients with atrial fibrillation: Journal of circulation Arrhythmia and electrophysiology (5). 312-8.

Gouya G, Arrich J, Wolzt M, et al., 2014, Antiplatelet treatment for prevention of cerebrovascular events in patients with vascular diseases: a systematic review and meta-analysis. Stroke,45(2):492-503. 
Graeme, J. H., Bo, N., Werner, H. \& Thorsten, S., 2014, Management of acute stroke in patients taking novel oral anticoagulants. International Journal of Stroke, (9) 627-632.

Gray, E., Hogwood, J. \& Mulloy, B., 2012, The Anticoagulant and Antithrombotic Mechanisms of Heparin, s.l.: Handb Exp Pharmacol, 207: 43-61.

Hankey GJ.,2010, Replacing aspirin and warfarin for secondary stroke prevention: is it worth the costs? .Curr Opin Neurol, 23(1):65-72.

Intercollegiate Stroke Working Party., 2012, National clinical guideline for stroke 4th ed. Royal college of physician, 66-70.

Kernan, W. N., Ovbiagele, B. \& Black, H. R., 2014, Guidelines for The Prevention of Stroke in Patients with Stroke and Transient Ischemic Attack; a guideline for healthcare professionals from the American Heart Association/American Stroke Association. In: Stroke: s.n., 45: 2160236.

Leithäuser B, Jung F, Park J-W., 2013, Oral anticoagulation for prevention of cardioembolic stroke in patients with atrial fibrillation: Focusing the elderly. Applied Cardiopulmonary Pathophysiology, 43-9.

Martin, D. et al., (2016), European Stroke Organisation (ESO) guidelines for prophylaxis for venous thromboembolism in immobile patients with acute ischaemic stroke. s.l.:European Stroke Journal, 64-72.

Ogilvie IM., Newton N .,Welher S., Lip GYH .,2009, Underuse of Oral Anticoagulants in Atrial Fibrillation: A Systematic Review; American Journal of Medicine, 123(7):635-45.

Olesen, J.B., Fauchier, L., Lane, D.A., Taillandier, S., Lip, G.Y., 2012, Risk factors for stroke and thromboembolism in relation to age among patients with atrial fibrillation. The Loire Valley Atrial Fibrillation Project (141), 147-53.

Shahpouri, M., Mousavi, S., Khorvash, F., et al., 2012, Anticoagulant therapy for ischemic stroke: A review of literature. J Res Med, 17 (4). 396-401.

Singer, D.E., Albers, G.W., Dalen, J.E., et al., 2008, Antithrombotic therapy in atrial fibrillation. 8th Edition. American College of Chest Physicians Evidence-Based Clinical Practice Guidelines, 396-401.

Yang, X. et al., 2016, Use of Warfarin at Discharge Among Acute Ischemic Stroke Patients With Nonvalvular Atrial Fibrillation in China, China National Stroke Registry II Investigation, 46470. 
